\title{
Testing the Validity of Proposed Model for Measuring the Crisis Management in the Central Tripoli Hospital-Libya "Using Confirmatory Factor Analysis"
}

\author{
Naser Ramadan Abu Oun ${ }^{1}$, Kamaluddin Nurdin Marjuni ${ }^{2}$ \\ ${ }^{1,2}$ Faculty of leadership and Management, Universiti Sains Islam Malaysia, Bandar BaruNilai, 71800 Nilai, Negeri Sembilan, Malaysia
}

\begin{abstract}
The current study attempts to develop a conceptual framework as a measurement of crisis management in health institutions by adopting its management methods as dimensions appropriate for measuring such crisis (transforming the crisis, tactical reserve, fragmenting the crisis, facing the crisis and containing the crisis). To achieve this research aim, the study applied a confirmatory factor analysis (CFA) using Amos. Based on the results, the study found that the model is a valid and reliable measurement of crisis management.
\end{abstract}

Keywords: Track the Crisis, Reserve the Crisis, fragmenting the crisis, Confrontation the Crisis, containing the crisis

\section{Introduction}

The current study focused its aim on developing a conceptual framework for crisis management, going beyond the traditional view that describes crisis as an event which is destructive or influential on the organization as a whole to the strategic view that describes crisis as a defining moment and a turning point for the better or the worse. The research addressed characteristics that distinguish a crisis from a catastrophe and a disaster in addition to the multiple levelpractices used for managing it. The present study also went beyond or exceeded the conventional classifications of single basis crisis, thus approaching crisis from its modern or recent classifications which rely more on solving it through methods that turn it into positive to disposal. And since the crisis results into several other accompanied crises at the same time, all of them need to be managed at one time. This study also highlighted the most important crisis which is the crisis in the hospital management that relies on the psychological side and is associated with humanitarian matter. It can be handled through its main methods of management, which are summarized as the followings (Augustine, 1995):

\subsection{Track the Crisis}

This method deals with the crises that are difficult or complicated to be faced by containing such crisis, absorbing or comprehending its consequences, bowingdown it, admitting its causes and then overcoming it and addressing its secretions/components and consequences in a way that leads to reducing its risks. Thus, according to this technique or method, the crisis manager should work in convincing those creators of such crisis or those people who create this crisis, luring and attracting them to turn their destructive capabilities into other positive paths.

\subsection{Reserve the Crisis}

According to this technique or way of crisis management, weaknesses and sources of crises are identified, and preventive tactical reserves are that can be used when a crisis emerges or occurs are formed. This method is often used in industrial organizations in the event of a crisis especially in raw materials or a lack of liquidity (Boin,2007).

\subsection{Fragmenting the Crisis}

This method is known as the best and most preferable method especially when the crisis is severe and dangerous. It also relies or depends on studying all aspects of the crisis to form a better understanding and knowledge of the powers that constitute up the alliances of the crisis and to determine a framework of the conflicting interests and the potential benefits of the members of these alliances. Following this striking them by creating leaders and finding gains of these trends that are conflicting with continued crisis alliances. By so doing, the major crisis turns into small fragmented crises.

\subsection{Confrontation the Crisis}

It is known as one of the most difficult non-traditional ways of dealing with crises and therefore, it is called the method of violent confrontation. This method is often used in case of lack of information or in the case of an existing certainty that there is no alternative.

\subsection{Containing the Crisis}

This method depends on scoping the crisis in a very narrow and limited range. Examples of such crises are labor crises where dialogue and understanding method is used with the leaders of those crises. Thus, this method means scoping or limiting the crisis in a narrow and limited scope and fixing it at the stage where it reached while at the same time, working hard to absorb and assimilate the pressures causing such crisis, thus, making it lose its destructive power. 


\section{International Journal of Science and Research (IJSR) \\ ISSN (Online): 2319-7064}

Index Copernicus Value (2013): 6.14 | Impact Factor (2014): 5.611

\section{Research Objectives}

The current study aimed to test the validity of a proposed model for measuring Crisis Management in the Central Tripoli Hospital-Libya

\section{Method}

\subsection{The Study Population}

The population of the current study is represented by managers of departments and their assistants as well as heads of departments and administrative units in the Central Tripoli Hospital in Libya. Due to the small study population, the researcher adopted a total population sampling (the entire population) which is estimated (565) individuals, but after distributing the survey to the study population, retrieval and examination of it, it was found that the number is (413) which represents the valid returned questionnaires used for the data analysis.

\subsection{Research Instruments}

In this regard, it is relied upon the questionnaire as a tool to gather the necessary information for this study as one of the most suitable scientific research tools that achieve the survey study objectives and to obtain information and facts associated with a determined reality, for achieving the study, a questionnaire is made for the purposes of processing the studying test the validity of a proposed model for measuring Crisis Management.

\subsection{Confirmatory Factor Analysis}

In order to test the validity constructs and the research hypotheses the Structural Equation Modeling (AMOS) model-fitting program is used. The model fit is evaluated by using four indices of the model goodness-of-fit: (1) the comparative fit index (CFI) (2) the chi-square statistics McDonald and Marsh (1990); (3) (RMSEA) between (0.08) to (0.10) indicates a mediocre fit Browne and Cudeck (1993) and would not employ a model a RMSEA greater than 0.1 $(>0.1)$ (MacCallu um et al., 1996). (4) the minimum value of the discrepancy between the observed data and the hypothesised model divided by degrees of freedom (CMIN/DF) or normed chi-square. Marsh and Hocevar (1985);

\subsection{Construct Validity}

According to Hair,Black,Babin, Anderson and Tatham (2006) the employment of factor loading composite reliability (CR) and average variance extracted (AVE) to determine the convergent validity if it equals to or greater than $0.5(\geq 0.5)$ and the composite reliability equals to or greater than 0.7 $(\geq 0.7)$ if were recommended by Hair et al.(2006). Also, (AVE) reading values should be greater than $0.5(\geq 0.5)$ (Fornel and Larker,1981).

\section{Results}

\subsection{The Modified Model}

From Figure (1) that shows the results of the (CFA) for the proposed model for measuring Crisis Management, it is evident that the model is free of the illogical correlation since it reaches or exceeds the integer (1). This also indicates that there is not any problems in the (CFA) used for testing the validity of this model that comprises five factors: The first factor including the Containment the Crisis, the second factor including the Reserve the Crisis and the third factor containing the Track the Crisis, the fourth factor containing theFragmentation the Crisis, the fifth factor containing the Confrontation the Crisis. As seen in Figure (1) and Table (1), the indicators of agreement between the model and the data exceeded the $\mathrm{T}$-value, thus, implying that there is disagreement between Crisis Management and the data of the sample since the value of the Chi-Square was (1541.949) and the degree of freedom was (289), and the level of significance was $(\mathrm{P}=.000)$. In addition, we can see that the normative ChiSquare (Chi-Square /degrees of freedom) was (5.335) being higher than (5), and the value of relative strength index (CFI) was (.855) less thanthe T-value (.90). The results also show that the value of the index (RMSEA) error square was (.103) being higher than (.080). Due to this contradiction between the model and the data, it was necessary to modify the Crisis Management model in this study.

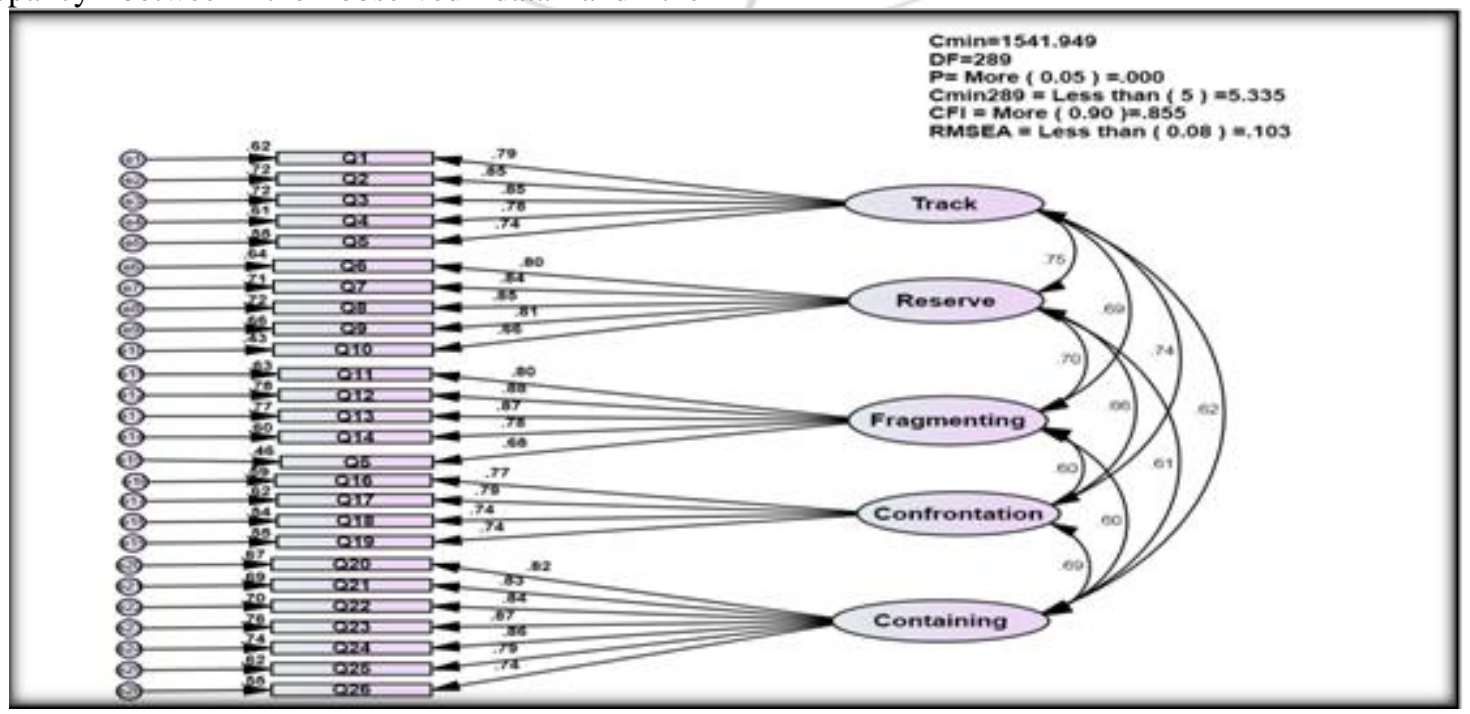

Figure 1: Model Crisis Management before the amendment

Volume 5 Issue 2, February 2016 


\section{International Journal of Science and Research (IJSR) \\ ISSN (Online): 2319-7064 \\ Index Copernicus Value (2013): 6.14 | Impact Factor (2014): 5.611}

In order to modify this model, we followed was deleting (Q22-Containment).In addition to linking some of the items according to what is shown in Figure (2). And to what Amos confirmed by analysis of Amos.

Table 1: index value of Crisis Management model before and after modification

\begin{tabular}{|c|c|c|c|}
\hline indicators consistency & index value before modification & index value after modification & $\begin{array}{c}\text { Function value on the quality of } \\
\text { conformity }\end{array}$ \\
\hline Cmin & 1541.949 & 930.156 & --- \\
\hline $\mathrm{df}$ & 289 & 259 & Non \\
\hline P & .000 & .000 & Less than (5) \\
\hline Cmin/Df & 5.335 & 3.591 & More (0.90) \\
\hline CFI & .855 & .917 & Less than $(0.08)$ \\
\hline
\end{tabular}

\subsection{Confirmatory Factor Analysis of the Crisis Management model}

The results of the goodness-of-fit of the final revised of the Crisis Management model showed that normed chi- square (CMIN/DF) was (3.591); the (CFI) was (.917) and Rmseawas (.079). Figure (2) shows the adequacy of the final revised of the Crisis Management model.

\subsection{Construct Validity and Reliability}

4.3.1Track the Crisis: In the present study, lodging for the parameters factor ranged from 0.64 to 0.90 , with all parameters were above $0.5(\geq 0.5)$. The reliability was greater than $0.7(\geq 0.7)$, it ranged from 0.96 to 0.97 . In addition, the AVE reading was 0.64 where the value was greater than 0.5 $(\geq 0.5)$. Consequently, all results fulfilled the AVE, and the reliability discriminant validity of the model. In general, The first Dimensionof the Crisis Management modelwas fit and fulfilled the construct as depicted in Table (2).

Table 2: Construct Validity and Reliability of Crisis Management model-Track the Crisis

\begin{tabular}{|c|c|c|c|c|c|c|c|c|c|}
\hline Item code & Items & Reliability & estimate & S. E. & C. R. & $\mathrm{P}$ & Loading & $\mathrm{R}$ & AVE \\
\hline Q1 & $\begin{array}{l}\text { The administration of the hospital conducts the necessary } \\
\text { studies to determine the conflicting interests causing the } \\
\text { crisis }\end{array}$ & .96 & 1.000 & - & - & - & .81 & .65 & .64 \\
\hline Q2 & $\begin{array}{l}\text { The administration of the hospital depends on experts and } \\
\text { specialists who can fragment the crisis successfully }\end{array}$ & .96 & 1.055 & .049 & 21.38 & 0.00 & .90 & .80 & - \\
\hline Q3 & $\begin{array}{l}\text { The administration of the hospital is usually able to } \\
\text { fragment the crisis successfully }\end{array}$ & .96 & 1.011 & .049 & 20.70 & 0.00 & .87 & .76 & - \\
\hline Q4 & $\begin{array}{l}\text { I am careful about the speedy collection of adequate and } \\
\text { accurate information on the crisis in order to face it easier }\end{array}$ & .97 & .880 & .053 & 16.70 & 0.00 & .75 & .56 & - \\
\hline Q5 & I put a comprehensive plan to tackle the crisis & .96 & .772 & .056 & 13.78 & 0.00 & .64 & .41 & - \\
\hline
\end{tabular}

\subsubsection{Reserve the Crisis}

In the current study, the lodging for the parameters factor ranged from 0.60 to 0.86 , with all parameters were above $0.5(\geq 0.5)$. And the reliability was greater than $0.7(\geq 0.7)$, it ranged were 0.96 . In addition, the AVE reading was 0.62 where the value was greater than $0.5(\geq 0.5)$. Consequently, all results fulfilled the AVE, and the reliability discriminant validity of the factor. In general, the secondDimensionof the Crisis Management modelwas fit and fulfilled the construct as depicted in Table (3).

Table 3: Construct Validity and Reliability of Crisis Management model-Reserve the Crisis

\begin{tabular}{|c|c|c|c|c|c|c|c|c|c|}
\hline Item code & Items & Reliability & estimate & S. E. & C. $R$. & $P$ & Loading & $R$ & $A V E$ \\
\hline `Q6 & $\begin{array}{l}\text { There are clear administrative instructions that define the } \\
\text { procedures and how to deal with potential crises }\end{array}$ & .96 & 1.000 & - & - & - & .82 & .67 & .62 \\
\hline Q7 & $\begin{array}{l}\text { It is easy to obtain the human potentials required from other } \\
\text { sections when there is a need for them in order to deal with } \\
\text { the crisis }\end{array}$ & .96 & 1.062 & .052 & 20.49 & 0.00 & .86 & .75 & - \\
\hline Q8 & $\begin{array}{l}\text { The administration of the hospital has early warning systems } \\
\text { that help in detecting crises before they occur }\end{array}$ & .96 & 1.077 & .054 & 20.01 & 0.00 & .85 & .72 & - \\
\hline Q9 & $\begin{array}{l}\text { The administration of the hospital evaluates/ assesses } \\
\text { previous crisis management plans with the intention to } \\
\text { develop and improve them in order to deal with future crises }\end{array}$ & .96 & .948 & .054 & 17.64 & 0.00 & .77 & .60 & - \\
\hline Q10 & $\begin{array}{l}\text { There are clear administrative instructions that define the } \\
\text { procedures and how to deal with potential crises }\end{array}$ & .96 & .729 & .057 & 12.72 & 0.00 & .60 & .36 & - \\
\hline
\end{tabular}

\subsubsection{Fragmentation the Crisis}

In this study, the lodging for the parameters factor ranged from 0.67 to 0.89 , with all parameters were above $0.5(\geq 0.5)$. The reliability was greater than $0.7(\geq 0.7)$, it ranged were 0.96 . In addition, the AVE reading was 0.63 where the value was greater than $0.5(\geq 0.5)$. Consequently, all results fulfilled the AVE, and the reliability discriminant validity of the Dimension. In general, the third Dimension ofthe Crisis Management modelmodel was fit and fulfilled the construct as depicted in Table (4). 


\section{International Journal of Science and Research (IJSR) \\ ISSN (Online): 2319-7064 \\ Index Copernicus Value (2013): 6.14 | Impact Factor (2014): 5.611}

Table 4: Construct Validity and Reliability of Crisis Management model-Fragmentation the Crisis

\begin{tabular}{|c|c|c|c|c|c|c|c|c|c|}
\hline Item code & Items & Reliability & estimate & S. E. & C. $R$. & $P$ & Loading & $R$ & $A V E$ \\
\hline `Q11 & $\begin{array}{l}\text { I make/take quick, decisive and appropriate decisions to } \\
\text { address the crisis }\end{array}$ & .96 & 1.000 & - & - & - & .83 & .69 & .63 \\
\hline Q12 & I control the situation and direct it the right direction & .96 & 1.087 & .050 & 21.81 & 0.00 & .89 & .78 & - \\
\hline Q13 & $\begin{array}{l}\text { I work to scope the crisis in a specific and limited range } \\
\text { within the hospital so as not to spread }\end{array}$ & .96 & 1.009 & .050 & 20.11 & 0.00 & .84 & .70 & - \\
\hline Q14 & Working to freeze when the crisis stage reached by & .96 & .860 & .054 & 16.05 & 0.00 & .71 & .51 & - \\
\hline Q15 & $\begin{array}{l}\text { Work quickly and accurately on the movement of } \\
\text { material and human means necessary to contain the crisis }\end{array}$ & .96 & .831 & .056 & 14.82 & 0.00 & .67 & .45 & - \\
\hline
\end{tabular}

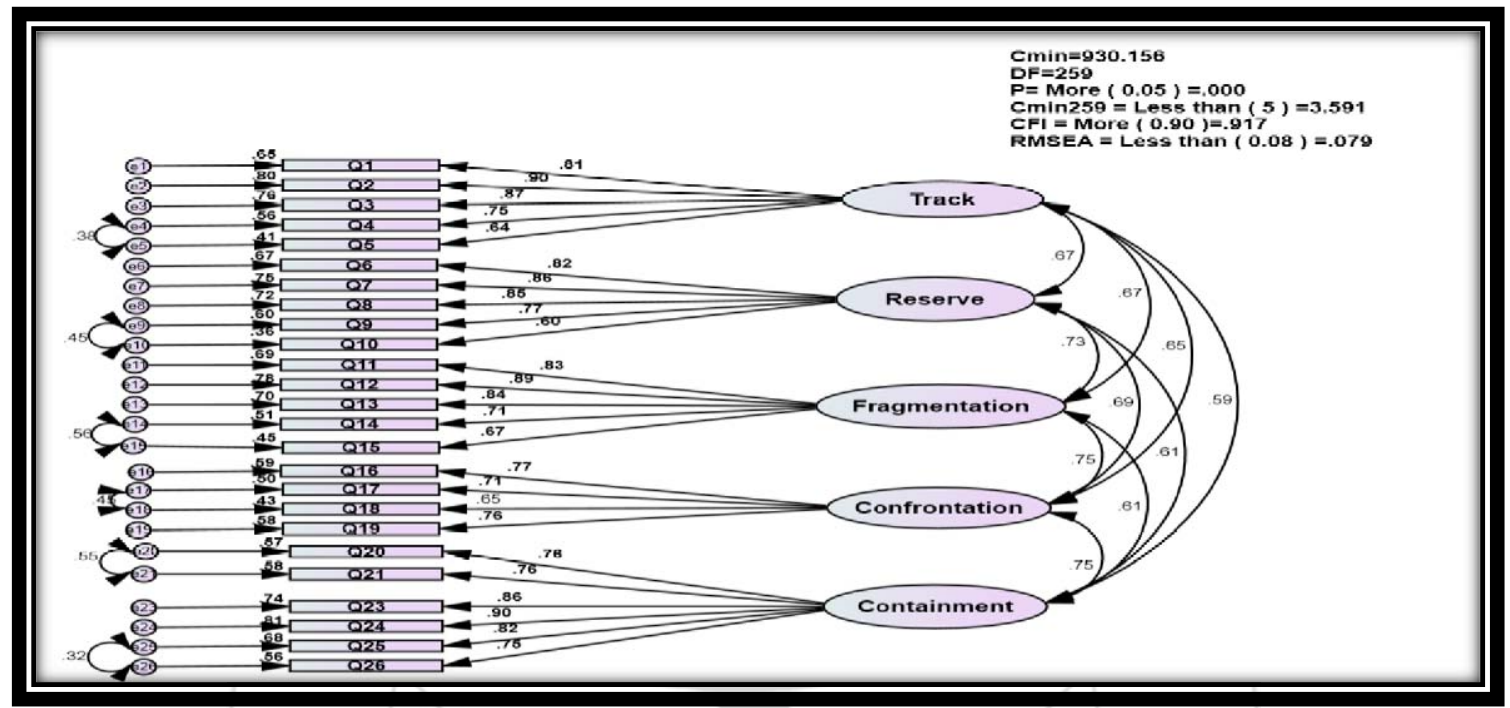

Figure 2: Crisis Management model after amendment

\subsubsection{Confrontation the Crisis}

In the present study, the lodging for the parameters factor ranged from 0.65 to 0.77 , with all parameters was above 0.5 $(\geq 0.5)$. The reliability was greater than $0.7(\geq 0.7)$, it ranged were 0.96 . In addition, the AVE readings was 0.53 where the value was less than $0.5 \quad(<0.5)$. In general, the fourth Dimension ofthe Crisis Management model model was fit and fulfilled the construct as depicted in Table (5).

Table 5: Construct Validity and Reliability of Crisis Management model-Confrontation the Crisis

\begin{tabular}{|c|c|c|c|c|c|c|c|c|c|}
\hline Item code & Items & Reliability & estimate & S. E. & C. R. & $\mathrm{P}$ & Loading & $\mathrm{R}$ & AVE \\
\hline `Q16 & $\begin{array}{l}\text { Absorb generating pressure necessary for the strength lost } \\
\text { affecting }\end{array}$ & & 1.000 & - & - & - & .77 & .59 & .53 \\
\hline Q17 & $\begin{array}{l}\text { working on not spreading rumors and exaggerations } \\
\text { talking about the crisis so as not to worsen their } \\
\text { occurrence }\end{array}$ & .96 & .871 & .063 & 13.83 & 0.00 & .71 & .50 & - \\
\hline Q18 & $\begin{array}{l}\text { The hospital management the adoption of specialized } \\
\text { teams from the inside to contain the crisis }\end{array}$ & .96 & .828 & .065 & 12.73 & 0.00 & .65 & .43 & - \\
\hline Q19 & $\begin{array}{l}\text { Managed the hospital management during the previous } \\
\text { years of the crisis management successfully }\end{array}$ & .97 & .944 & .063 & 15.04 & 0.00 & .76 & .58 & - \\
\hline
\end{tabular}

\subsubsection{Containment the Crisis}

Finally, in this study, the factor lodging for the parameters ranged from 0.75 to 0.90 , with all parameters were above (.5) $(\geq 0.5)$. The reliability ranged were 0.96 were greater than (0.7) ( $\geq 0.7$ ). Furthermore, the (AVE) readings was 0.66 where the value was greater than $(0.5)(\geq 0.5)$, all results fulfilled the (AVE), and The reliability discriminant validity of the model. Generally, the measurement model of the Crisis Management model was fit and fulfilled the construct as depicted in table (6).

Table 6: Construct Validity and Reliability of Crisis Management model-Containment the Crisis 


\section{International Journal of Science and Research (IJSR) \\ ISSN (Online): 2319-7064}

Index Copernicus Value (2013): 6.14 | Impact Factor (2014): 5.611

\begin{tabular}{|c|c|c|c|c|c|c|c|c|c|}
\hline Item code & Items & Reliability & estimate & S. E. & C. R. & $\mathrm{P}$ & Loading & $\mathrm{R}$ & Ave \\
\hline Q20 & $\begin{array}{l}\text { Previous crises had an impact on the performance of the } \\
\text { hospital }\end{array}$ & .96 & 1.000 & - & - & - & .76 & .57 & .66 \\
\hline Q21 & $\begin{array}{l}\text { The administration of the hospital is trying to draw the } \\
\text { public's attention to a topic different from the topic of crisis } \\
\text { that often tends to be positive }\end{array}$ & .96 & .975 & .041 & 23.90 & 0.00 & .76 & .58 & - \\
\hline Q22 & \begin{tabular}{|c|} 
The way the administration of the hospital deals and directs \\
a crisis is more dominated by the mental side than the \\
emotional side
\end{tabular} & .96 & 1.103 & .061 & 18.23 & 0.00 & .86 & .74 & - \\
\hline Q23 & $\begin{array}{c}\begin{array}{c}\text { The administration of the hospital provides the necessary } \\
\text { tools or means of communications related to crisis } \\
\text { management }\end{array} \\
\end{array}$ & .96 & 1.227 & .064 & 19.10 & 0.00 & .90 & .81 & - \\
\hline Q24 & $\begin{array}{l}\text { The administration of the hospital is aware of the } \\
\text { importance of a (Margin of Safety) for the inventory of } \\
\text { materials and the needs of the hospital }\end{array}$ & .96 & 1.073 & .062 & 17.34 & 0.00 & .82 & .68 & - \\
\hline Q25 & $\begin{array}{c}\text { The administration of the hospital usually provides a } \\
\text { sufficient inventory of requirements }\end{array}$ & .96 & .972 & .063 & 15.51 & 0.00 & .75 & .56 & - \\
\hline
\end{tabular}

\section{Conclusion}

The current study aimed to test the validity of a proposed model for measuring Management Crisis in the Central Tripoli Hospital-Libya. The proposed model included Management Crisis as a potential variable that is realized through five apparent factors(transforming the crisis, tactical reserve, fragmenting the crisis, facing the crisis and containing the crisis). To achieve this research aim, the researcher carried out a (CFA) by using the Amos program (Amos .21). This was test the validity of the model that can be used for measuring the Crisis Management. Based on the results of the analysis and the outputs of the Amos in Figure (1) and Table (1), it is evident that there is disagreement between the model and the data, which emphasizes the need to modify the model. After the model modification as illustrated by Figure (2) and Table (2), there was a match between the model and the sample data based on the goodness of fit indices. Moreover, the average variance extracted (AVE) of all the factors was higher than the standard test factors (.50). Therefore, it can be concluded that the proposed model in this study has both convergent and discriminate validity, which implies that the model is valid and reliable to be used for measuring of Management Crisis.

\section{References}

[1] Augustine,Norman (1995). Managing The Crisis You Tried To Prevent. Harvard

[2] Business Review. Nov.-Des.: 147-158.

[3] Boin ,Arjen\&McConnell , Allan (2007) ."Preparing for Critical InfrastructureBreakdowns :The Limits of Crisis Management \&the Need for Resilience ." Journal of Contingencies \& Crisis Management .Vol.(15) , No . (1):50-59.

[4] .Browne, M. W., \&Cudeck, R. (1993). Alternative ways of assessing model fit. "Sage.Focus Editions, 154, 136.

[5] .Hair, J. F., Anderson, R. E., Tatham, R. L. \& Black, W. C. (2006).Multivariate Data Analysis (5th ed.), New Jersey, Prentice-Hall.

[6] .McDonald, R. P., \& Marsh, H. W. (1990).Choosing a multivariate model: Noncentrality and goodness of fit. "Psychological Bulletin", 107(2), 247-255.

[7] MacCallum, R. C., Browne, M. W., \& Sugawara, H. M. (1996). Power Analysis and Determination of Sample
[8] Marsh, H. W., \&Hocevar, D. (1985). Application of confirmatory factor analysis to the study of self-concept: First-and higher order factor models and their invariance across groups. "Psychological bulletin", 97(3), 562582.http://dx.doi.org/10.1037/0033-2909.97.3.562 